\title{
Hyperbranched Poly(ferrocenylene)s Containing Groups 14 and 15 Elements: Syntheses, Optical and Thermal Properties, and Pyrolytic Transformations into Nanostructured Magnetoceramics
}

\author{
Matthias Häußler, ${ }^{1}$ Qunhui Sun, ${ }^{1}$ Kaitian Xu, ${ }^{1}$ Jacky W. Y. Lam, ${ }^{1}$ Hongchen Dong, \\ and Ben Zhong Tang, 1,2
}

Ben Zhong Tang is an associate professor of chemistry at The Hong Kong University of Science and Technology. His research interests include polymer chemistry and materials science, and his research group is working on the development of new polymeric materials with novel linear and hyperbranched conjugated molecular structures and unique electronic, optical, magnetic, mesomorphic, organizational, biological, and pharmaceutical properties.

Ben received his Ph.D. from Kyoto University and did his postdoctoral work at the University of Toronto. He worked as a visiting scientist in the Osaka Laboratory of Sumitomo Chemical Co. and as a senior scientist in the Central Laboratory of Neos Corp. He joined the Department of Chemistry at The Hong Kong University of Science and Technology in July 1994. He is currently on the advisory boards of the Journal of Inorganic and Organometallic Polymers and Materials, the Journal of Polymer Materials, and Polymer (Korea) and on the editorial boards of the Journal of Nanoscience and Nanotechnology and Acta Polymerica Sinica. He received a Distinguished Young Scholar Award from the National Science Foundation of China in 2002.

\begin{abstract}
A series of hyperbranched poly(ferrocenylene)s containing elements $(\mathrm{E})$ of groups $14[\mathrm{E}=\mathrm{Si}(h b-\mathbf{1})$, Ge $(h b-2)]$ and $15[\mathrm{E}=\mathrm{P}(h b-3), \mathrm{Sb}(h b-4)]$ are prepared in good isolation yields (up to $82 \mathrm{wt} \%$ ) by the salt-eliminative polycoupling of dilithioferrocene with tri- $\left(\mathrm{RECl}_{3}\right)$ or tetrachlorides of the elements $\left(\mathrm{ECl}_{4}\right)$. While the polymers with no or small $R$ groups are insoluble or partially soluble, those with long alkyl chains $\left(\mathrm{R}=\mathrm{C}_{n} \mathrm{H}_{2 n+1}\right.$ with $\left.n \geq 8\right)$ are

\footnotetext{
${ }^{1}$ Department of Chemistry, Institute of Nano Materials and Technology, The Hong Kong University of Science \& Technology, Clear Water Bay, Kowloon, Hong Kong, China.

2 To whom correspondence should be addressed. E-mail: tangbenz@ ust.hk
}

completely soluble and film forming. The polymers exhibit solution properties characteristic of hyperbranched macromolecules: e.g. $h b-1(18)$ shows a low intrinsic viscosity $([\eta]=0.02 \mathrm{dL} / \mathrm{g})$ despite its high absolute molecular weight $\left(M_{\mathrm{w}}=5 \times 10^{5}\right)$. Spectroscopic analyses reveal that the polymers possess rigid skeleton structures with extended conjugations, with their absorption spectra tailing into the infrared region $(>700 \mathrm{~nm})$. The polymers show good thermal stability with $T_{\mathrm{d}}$ up to $\sim 400^{\circ} \mathrm{C}$ and can be graphitized into iron-containing ceramics when pyrolyzed at high temperatures, with char yields up to $\sim 60 \mathrm{wt} \%$. While calcinations of the Si-containing polymers $(h b-\mathbf{1})$ at $1000^{\circ} \mathrm{C}$ under nitrogen give ceramics containing mostly $\alpha-\mathrm{Fe}$ nanoparticles, those of $\mathrm{Ge}-(h b-2)$ and Sb-containing 
polymers ( $h b-4)$ are completely transformed into their ironalloys. The ceramics from the P-containing polymers $(h b-\mathbf{3})$ show diffraction patterns of iron phosphides. Iron silicide nanocrystals of "large" sizes are obtained when the pyrolysis of $h b-\mathbf{1}$ is conducted at a high temperature of $1200^{\circ} \mathrm{C}$ under argon. This ceramic is highly magnetizable ( $M_{\mathrm{s}}$ up to $\sim 51 \mathrm{emu} / \mathrm{g}$ ) and shows near-zero remanence and coercivity; in other words, it is an outstanding soft ferromagnet with a high magnetic susceptibility and practically nil hysteresis loss.

KEY WORDS: Hyperbranched poly(ferrocenylene)s; organometallic polymers; magnetic ceramics; nanostructured materials.

\section{INTRODUCTION}

The development of processable organic polymers with useful material properties have been under constant pursuit for many decades, with the research efforts on conjugated polymers surging since the seminal discovery of the high electrical conductivity of doped polyacetylene [1-3]. We have worked on the syntheses of new conjugated organic polymers of polyenes [4], polyarylenes [5] and polyynes [6] and have discovered a variety of functional properties of the polymers including liquid crystallinity, light emission, photoconductivity, solvatochromism, optical nonlinearity, helical chirality, self-assembling, biocompatibility, thermal curability, metal complexation and pyrolytic ceramization [7-17]. We have recently launched a research program on the preparations of hyperbranched macromolecules with metal and metalloid species embedded in the organic frameworks [18-21], with the aim of generating new organometallic polymers that will exhibit electronic, optical and magnetic properties inaccessible by their pure organic parents [22-25].

Ferrocene is probably the most prominent example of an organometallic species. Stringing ferrocene rings together leads to the formation of linear polyferrocene chains. The ring-opening polymerizations of silaferrocenophanes yield poly(ferrocenylenesilene)s [25,26], which show an array of novel functional properties and have served as processable polymer precursors to ceramic materials $[27,28]$. We have been interested in knitting ferrocene rings into nonlinear hyperbranched poly(ferrocenylene) spheres. With their three-dimensional molecular structures, the polymers can be heavily loaded with ferrocene rings and can hold the metallic atoms inside the nanoreactor sites during the ceramization processes. The hyperbranched polymers are thus expected to be excellent precursors to advanced ceramics in terms of offering the opportunity of forming large metallic nanocrystals in high yields.

In this account, we briefly review our work on the syntheses of hyperbranched silicon-containing poly(ferrocenylene)s as well as summarizing the latest outcomes of our extended research efforts on the integration of other groups 14 and 15 elements including germanium, phosphorus, and antimony into the poly(ferrocenylene) framework. The hyperbranched structure endows the organometallic polymers with excellent thermal stability and enhances their electronic conjugations. Pyrolyses of the polymers furnish ceramics containing iron- and iron-alloy nanoclusters in high yields, which are found to show excellent soft ferromagnetism.

\section{POLYMER SYNTHESES}

The hyperbranched poly(ferrocenylene)s are prepared by the desalt polycoupling of dilithioferrocene $\left(\mathrm{FcLi}_{2}\right)$ with various metalloid chlorides under vigorously dried and strictly controlled polymerization conditions (Schemes 1 and 2). $\mathrm{FcLi}_{2}$ readily reacts with $\mathrm{CH}_{3} \mathrm{SiCl}_{3}$, furnishing poly[1,1'-ferrocenylene-(methyl)silyne] $[h b-\mathbf{1}(1)]$ in high yield $(\sim 71 \%$, Table I, No.1). The polymer is, however, only partially soluble. Introducing a long alkyl chain into the molecular structure of the polymer should loosen the rigid polyferrocene framework and hence lead to an improved solubility. Delightfully, this solvating approach works well and the polymer with a flexible $n$-octyl chain $[h b-1(8)]$ is completely soluble in common solvents. Increasing the alkyl chain length to 12 or more carbon atoms contributes to enhanced molecular weights and polymer yields. Different from their congers with short alkyl chains, polymers $h b-\mathbf{1}(12)$ and $h b-\mathbf{1}(16)$ appear as brown elastomers, due to their low glass transition temperatures $\left(T_{\mathrm{g}}\right)$ induced by the internal plasticizing effect of the long, flexible $n$-dodecyl and $n$-hexadecyl chains.

With a further increase in the length of the alkyl chain to $n$-octadecyl, the molecular weight of the resultant polymer $[h b-\mathbf{1}(18)]$ reaches a high $M_{\mathrm{w}}$ value of 12000 (Table I, No. 5). It is well known that the size-exclusion chromatograph (SEC), when calibrated with standards of linear polymers (in this case polystyrene), often underestimates the molecular weights of hyperbranched polymers. Determination of the absolute molecular weight of polymer 


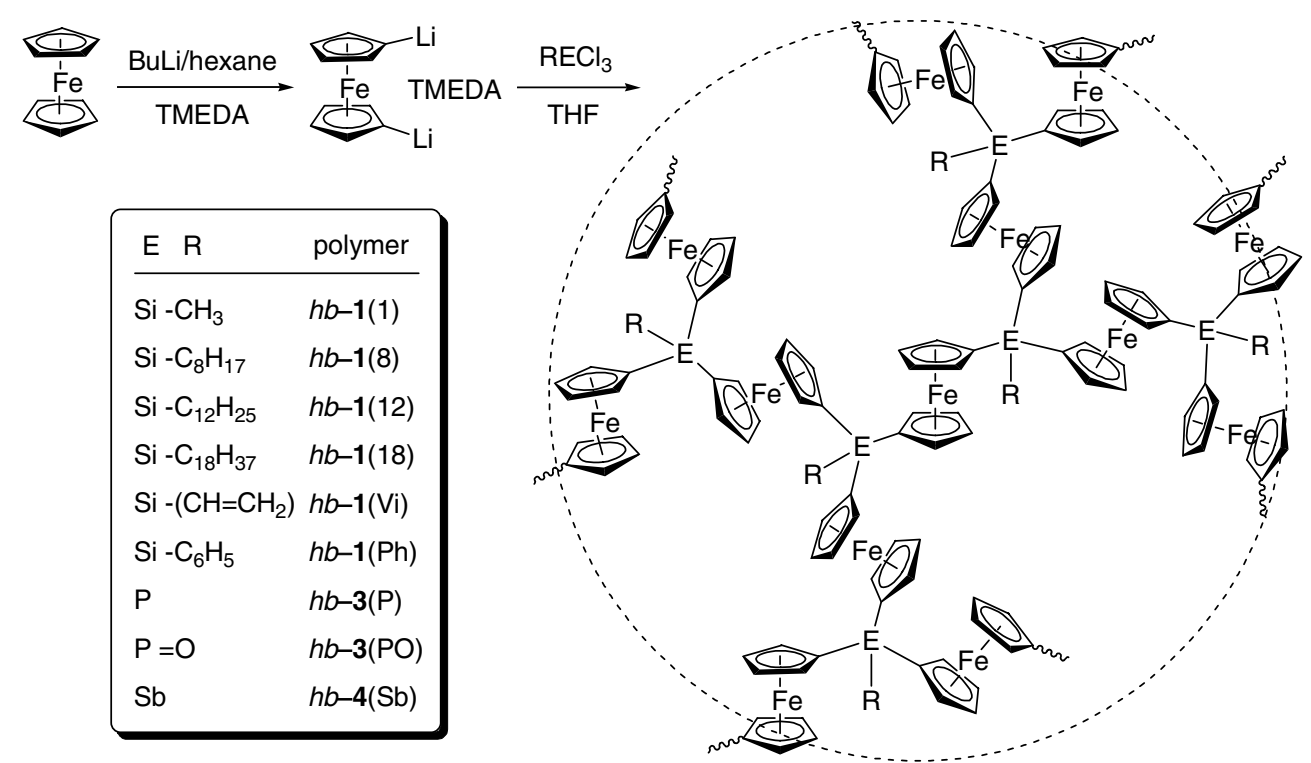

Scheme 1. Syntheses of Hyperbranched Poly(ferrocene)s by Desalt Polycoupling of Dilithioferrocene with Trichlorides of Silicon, Phosphorus and Antimony.

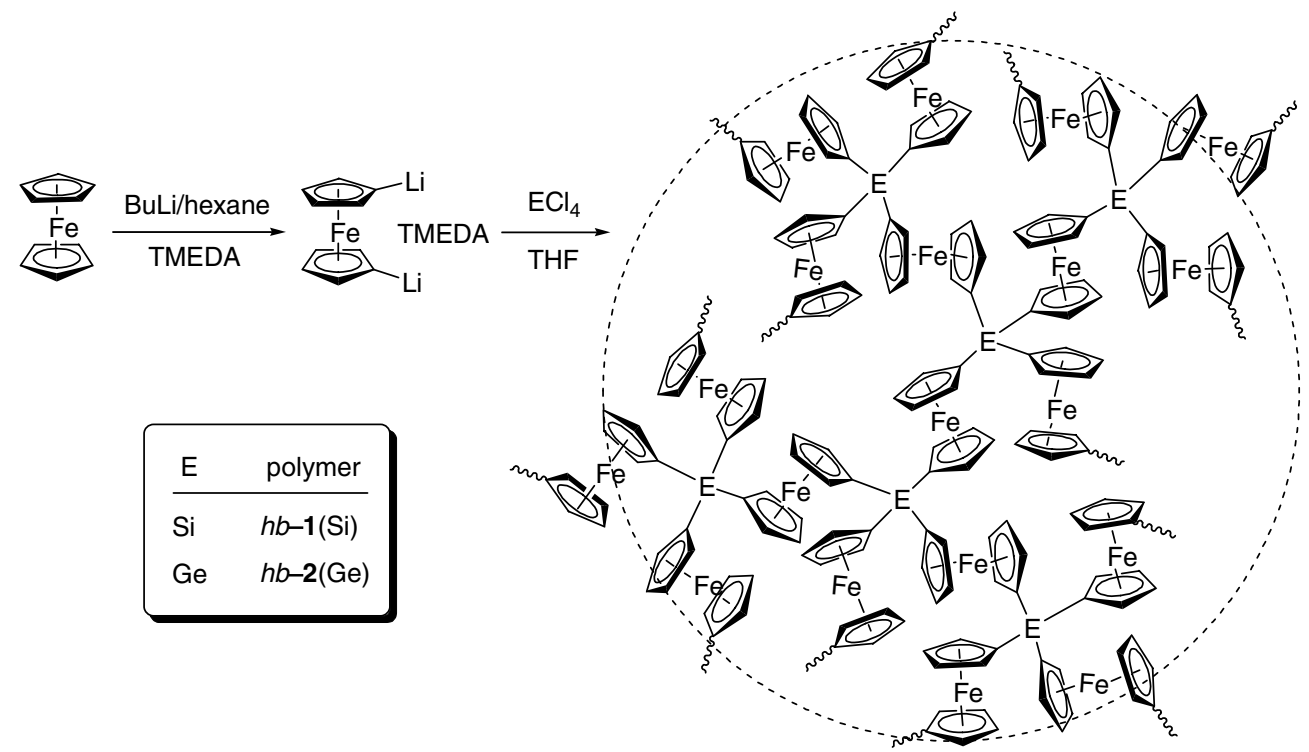

Scheme 2. Syntheses of Hyperbranched Poly(ferrocene)s by Desalt Polycoupling of Dilithioferrocene with Tetrachlorides of Silicon and Germanium.

$h b-1(18)$ by an SEC system equipped with lightscattering and viscometer detectors gives an $M_{\mathrm{w}}$ value of $5 \times 10^{5}$, which is much higher than the relative $M_{\mathrm{w}}$ value estimated by the SEC system calibrated with the linear polystyrene standards. Meanwhile, the intrinsic viscosity $([\eta])$ of $h b-\mathbf{1}(18)$ determined by the viscometer is as low as $0.02 \mathrm{dL} / \mathrm{g}$. A hyperbranched polymer is often characterized by high molecular weight but low intrinsic viscosity. The high $M_{\mathrm{w}}$ and low $[\eta]$ values of $h b-\mathbf{1}(18)$ thus prove its hyperbranched molecular structure. Replacing the alkyl chain at the $\mathrm{Si}$ atom by other groups such as vinyl or phenyl groups or changing the nature of the metalloid species from $\mathrm{Si}$ to Ge, $\mathrm{P}$ and $\mathrm{Sb}$ all results in the formation of partly or completely insoluble materials. 
Table I. Syntheses of Hyperbranched Poly(ferrocenylene)s ${ }^{a}$ Containing Groups 14 and 15 Elements

\begin{tabular}{rlccccc}
\hline No. & Polymer & Yield $(\mathrm{wt} \%)$ & Solubility & $M_{w}^{\mathrm{c}}$ & $M_{w} / M_{n}^{c}$ & Appearance \\
\hline 1 & $h b-\mathbf{1}(1)$ & 71.1 & $\Delta$ & $2000^{d}$ & $2.0^{d}$ & Golden yellow powder \\
2 & $h b-\mathbf{1}(8)$ & 67.5 & $\sqrt{ }$ & 2600 & 1.5 & Amber powder \\
3 & $h b-\mathbf{-}(12)$ & 77.0 & $\sqrt{ }$ & 6300 & 3.8 & Brown elastomer \\
4 & $h b-\mathbf{1}(16)$ & 52.0 & $\sqrt{ }$ & 9800 & 4.3 & Brown elastomer \\
5 & $h b-\mathbf{-}(18)$ & 72.3 & $\Delta$ & 11900 & 7.3 & Golden yellow powder \\
6 & $h b-\mathbf{1}(\mathrm{Vi})$ & 32.0 & $\Delta$ & $1300^{d}$ & $1.6^{d}$ & Golden yellow powder \\
7 & $h b-\mathbf{1}(\mathrm{Ph})$ & 62.0 & $\Delta$ & $3100^{d}$ & $3.8^{d}$ & Brown powder \\
8 & $h b-\mathbf{1}(\mathrm{Si})$ & 44.5 & $870^{d}$ & $1.7^{d}$ & Brown powder \\
9 & $h b-\mathbf{2}(\mathrm{Ge})$ & 76.5 & $1150^{d}$ & $1.9^{d}$ & Amber powder \\
10 & $h b-\mathbf{3}(\mathrm{P})$ & 81.7 & $\times$ & & Dark brown powder \\
11 & $h b-\mathbf{3}(\mathrm{PO})$ & 33.0 & $\times$ & & & Dark brown powder \\
12 & $h b-\mathbf{4}(\mathrm{Sb})$ & 73.4 & $\times$ & & Golden yellow powder \\
\hline
\end{tabular}

${ }^{a}$ Polymerization reactions carried out under nitrogen in THF at $-78^{\circ} \mathrm{C}$ for $24 \mathrm{~h}$ (Nos. 1-6) or at room temperature for $16 \mathrm{~h}$ (Nos. 7-12).

${ }^{b}$ Tested in common solvents such as dichloromethane, chloroform, toluene, dioxane, acetone, THF, DMF, and DMSO; symbols: $\times=$ insoluble, $\Delta=$ partially soluble, and $\sqrt{ }=$ completely soluble.

${ }^{c}$ Estimated by SEC in THF on the basis of a polystyrene calibration.

${ }^{d}$ For the THF-soluble fraction.

\section{STRUCTURAL CHARACTERIZATION}

Since some of the hyperbranched poly(ferrocenylene)s are partially or completely insoluble, FTIR spectroscopy is used to characterize their molecular structures. The overtone and combination bands of the ferrocene moieties $(\mathrm{Fc})$ in the range of $1750-1600 \mathrm{~cm}^{-1}$ as well as their vibration and deformation bands with peak maximums at $\sim 1036$ and $\sim 831 \mathrm{~cm}^{-1}$ are readily observed in the spectra of the polymers (Fig. 1) [29,30]. Additionally, the metalloid-ferrocene (EFc) bands appear at 1421 and $1166 \mathrm{~cm}^{-1}, \quad 1431$ and $1151 \mathrm{~cm}^{-1}, \quad 1420$ and $1183 \mathrm{~cm}^{-1}$, and 1411 and $1136 \mathrm{~cm}^{-1}$ for the $\mathrm{Si}-$, Ge-, P-, and Sb-containing polymers. These spectroscopic assignments confirm that the structures of the polymers are consisted of ferrocene and metalloid moieties. Furthermore, no absorption bands associated with such structures as silane $(\mathrm{Si}-\mathrm{H})$ or siloxane $(\mathrm{Si}-\mathrm{O}-\mathrm{Si})$ are observed at $\sim 2200$ and $\sim 1100 \mathrm{~cm}^{-1}$ [29].

Two broad resonance peaks at $\delta 4.12$ and 0.55 , associated respectively with the resonances of the cyclopentadienyl $(\mathrm{Cp})$ and methyl $(\mathrm{Me})$ protons, are observed in the ${ }^{1} \mathrm{H}$ NMR spectrum of the soluble fraction of polymer $h b-1$ (1) (Fig. 2). The ratio of the integrated areas of the resonance peaks of the $\mathrm{Cp}$ and Me protons is 1:0.26, identical (within experimental errors) to the theoretically predicted value of $12: 3$ (or $1: 0.25)$ for a repeating unit consisting of 1.5 ferrocenylene and 1 methyl group. The broadness of the absorption peaks is indicative of the structural complexity of the three-dimensional hyperbranched polymer arising from the variations in the chemical environment where the protons locate.

The poor solubility of the hyperbranched polymers with small $\mathrm{R}$ groups makes it difficult to

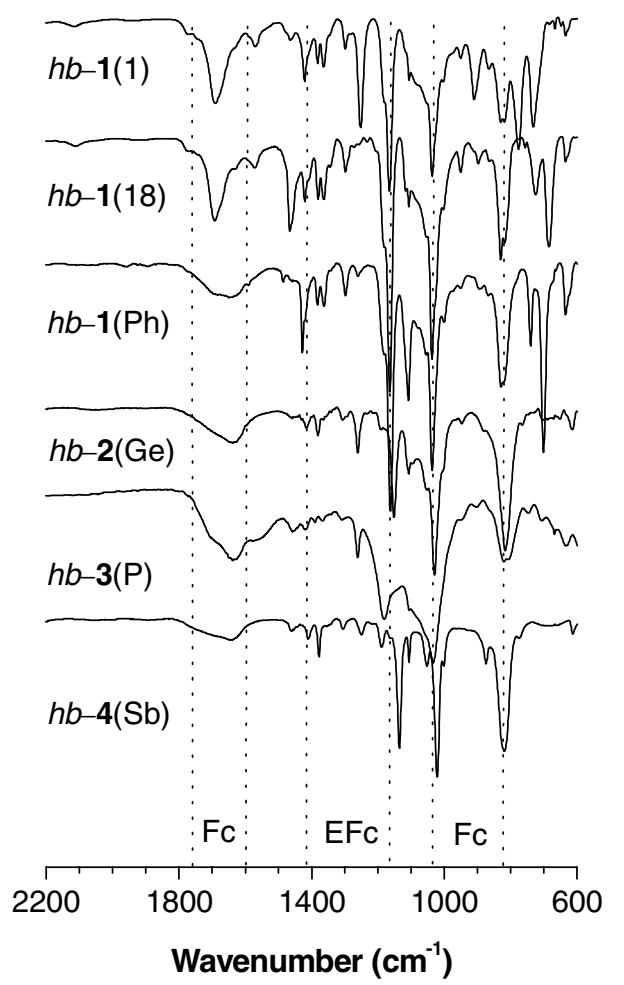

Fig. 1. IR spectra of hyperbranched poly(ferrocenylene)s containing groups 14 and 15 elements; $\mathrm{E}=$ element; $\mathrm{Fc}=1,1^{\prime}$-ferrocenylene. 


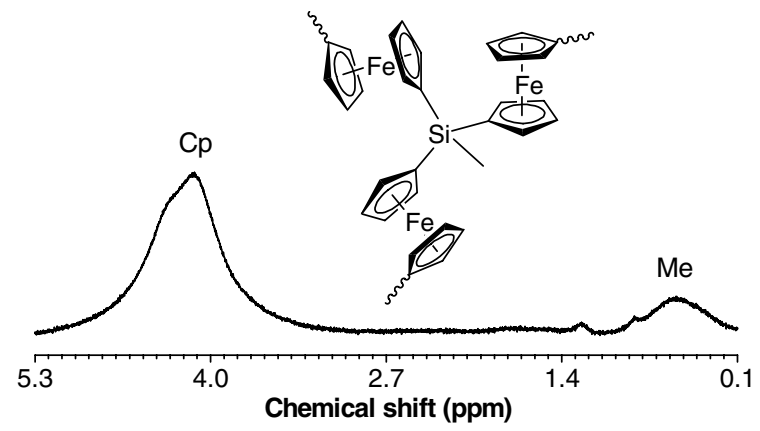

Fig. 2. ${ }^{1} \mathrm{H}$ NMR spectrum of a chloroform- $d$ solution of the soluble fraction of hyperbranched poly[1,1'-ferrocenylene(methyl)silyne] $[h b-\mathbf{1}(1)]$.

measure their ${ }^{13} \mathrm{C}$ NMR spectra. Polymers with long alkyl chains are much easily dissolved, which enables us to obtain ${ }^{13} \mathrm{C}$ NMR spectra of good quality. An example of the ${ }^{13} \mathrm{C}$ NMR spectra is shown in Fig. 3. The ipso carbon atoms of the $\mathrm{Cp}$ ring give three resonance peaks: two small but clearly observable ones at $\delta 73.15$ and 70.93 , and another partially observable one underneath the big peak of the other carbon atoms of the $\mathrm{Cp}$ ring. These three peaks may be associated with the absorptions of the ipso carbon atoms in the dendritic, linear and terminal units [31], each of which locates in a different microstructure environment, although we do not know the exact assignments of the peaks at present time. The carbon atoms of the alkyl group resonate in the upfield $(\delta \sim 35-10)$. Close inspection of the carbon resonances reveals that the carbon atoms located closer to the silicon core give weaker, broader "peaks", in comparison to those located far apart from the core. Such phenomenon has often been observed in polys-

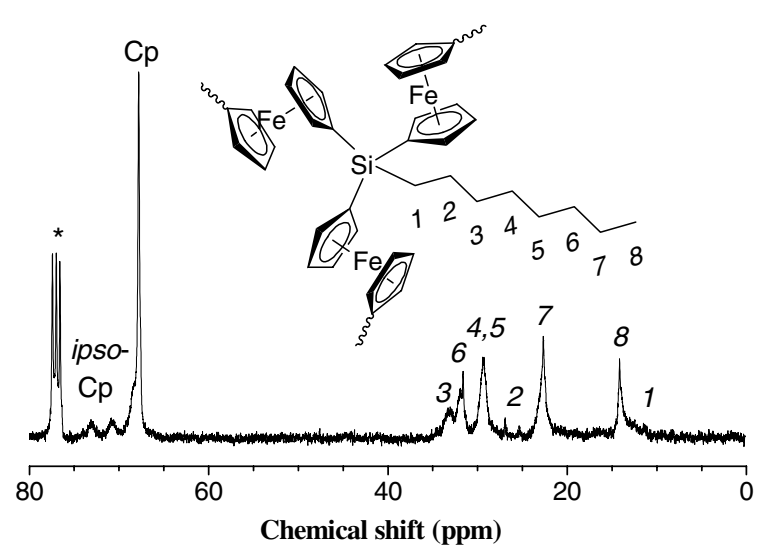

Fig. 3. ${ }^{13} \mathrm{C}$ NMR spectrum of a chloroform- $d$ solution of hyperbranched poly[1,1'-ferrocenylene( $n$-octyl)silyne] [hb-1(8)]. The solvent peaks are marked with an asterisk (*). ilyne systems, in which the resonance signal of the carbon atom directly attached to the silicon atom (C1) can be totally missing or completely unobservable [32]. This suggests that, similar to polysilynes, the hyperbranched poly(ferrocenylene)s containing different metalloid species also possess rigid molecular structures.

\section{ELECTRONIC ABSORPTIONS}

All the soluble poly(ferrocenylenesilyne)s, viz., $h b-\mathbf{1}(8)-\mathbf{1}(18)$, absorb in the UV-Vis spectral region, with their absorption spectra tailing into the infrared region (>700 nm) (Fig. 4). The maximum molar absorptivity $\left(\varepsilon_{\max }\right)$ increases with an increase in the alkyl chain length. On the other hand, $l-\mathbf{1}(1,1)$, a linear congener of $h b-1(1)$ with two methyl groups attached to the $\mathrm{Si}$ atom, shows a lower $\varepsilon_{\max }$ in the UV region and a shorter-wavelength band edge in the visible region. The higher molar absorptivities and longer wavelength band edges of the hyperbranched polymers indicate that they possess more extended $\sigma-\pi$ conjugations between the silyne moiety and the $\mathrm{Cp}$ ring than do their linear counterparts [33-36]. The UV-Vis absorption spectra of the remaining partly soluble and insoluble polymers are not given because it is difficult to accurately determine their solution concentrations and hence their molar absorptivities.

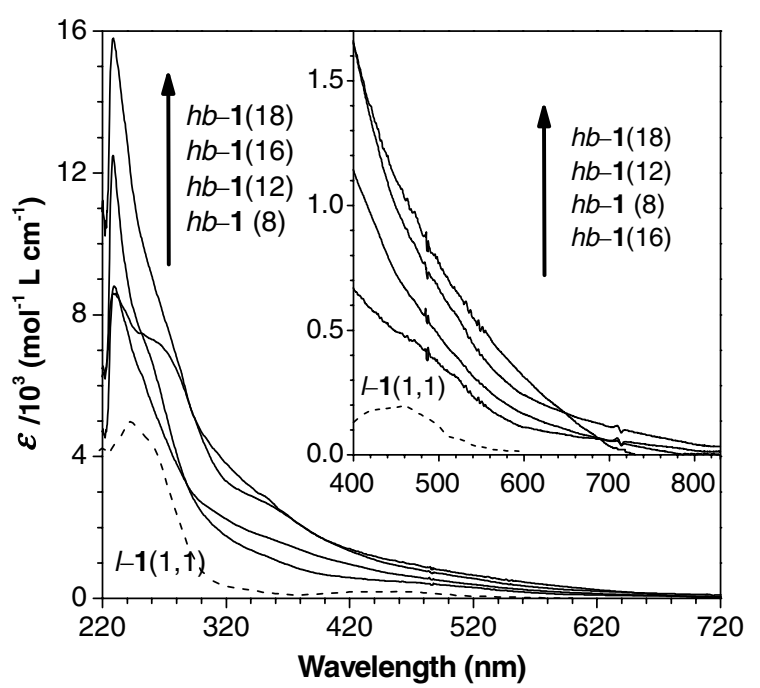

Fig. 4. UV-Vis spectra of soluble hyperbranched poly(ferrocenylenesilyne)s $-\left[\mathrm{Fc}_{3 / 2}\left(n-\mathrm{C}_{m} \mathrm{H}_{2 m+1}\right) \mathrm{Si}\right]_{n}-[h b-\mathbf{1}(m) ; m=8-18]$ in dichloromethane. The data for a linear poly $\left[1,1^{\prime}\right.$-ferrocenylene(dimethyl) silene] $[l-\mathbf{1}(1,1)]$ in THF is shown for comparison. 


\section{THERMAL TRANSITIONS}

As shown in Table I, the physical appearance of the hyperbranched poly(ferrocenylenesilyne)s varies with the length of their alkyl tails (from powdery to elastomeric and then back to powdery). To learn the cause for this change in the physical state, differential scanning calorimetry (DSC) analysis is employed to investigate the thermal transitions of the polymers. Figure 5 shows the DSC thermogram recorded in the second heating scan on polymer $h b-\mathbf{1}(16)$. The thermogram is clearly artifact-free, from which the glass transition temperature $\left(T_{\mathrm{g}}\right)$ and the melting point $\left(T_{\mathrm{m}}\right)$ of the polymer can be readily determined.

The thermal transition parameters obtained from the DSC analyses are summarized in Table II. The polymer with a small methyl group $h b-\mathbf{1}(1)$ undergoes no melting transition but a glass transition at $\sim 53^{\circ} \mathrm{C}$. When the $\mathrm{R}$ substituent changes to the longer vinyl group, $T_{\mathrm{g}}$ decreases to $40^{\circ} \mathrm{C}$. When the number of the carbon atoms in the alkyl chains $(m)$ increases from 8 to $18, T_{\mathrm{g}}$ monotonically decreases from 0 to ca. $-70^{\circ} \mathrm{C}$. Compared to their linear poly[ $\left[1,1^{\prime}\right.$-ferrocenylene(di- $n$-alkyl)silene $]$ counterparts $l-1(m, m)[36]$, the hyperbranched poly[1,1'-ferrocen-

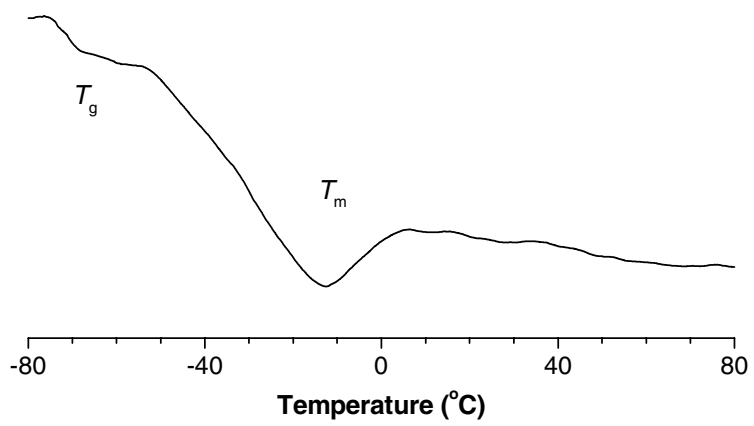

Fig. 5. DSC thermogram of poly $\left[1,1^{\prime}-\right.$ ferrocenylene $(n$-hexadecyl)silyne] $[h b-1(16)]$ measured under nitrogen at a heating rate of $10^{\circ} \mathrm{C} /$ min during the second heating scan after the polymer sample had been annealed at $150^{\circ} \mathrm{C}$ for $10 \mathrm{~min}$. ylene(n-alkyl)silyne]s [ $h b-\mathbf{1}(m)]$ exhibit higher $T_{\mathrm{g}}$ 's $\left(\Delta T>20^{\circ} \mathrm{C}\right.$; Fig. 6). This is a reflection of the rigid molecular structure of $h b-\mathbf{1}$ : the hyperbranched polymers possess three rigid $\mathrm{Cp}$ rings in one of their constitutional repeat units, while the linear polymers have only two $\mathrm{Cp}$ rings in one of their monomer units. The glass transition temperatures of $h b-\mathbf{1}(m)$ sharply decrease with an increase in $m$ when $m$ is small, but the extent of change (or the slope of the $T_{\mathrm{g}}-m$ plot) becomes smaller when $m$ becomes larger. This is probably caused by the antagonistic effect of the partial crystallization of the long alkyl chains, which hampers the segmental movements of the polymer branches, a well-known phenomenon for liquid-crystalline polymers [37].

From the DSC analyses we have learned that the hyperbranched polymers with short alkyl chains are amorphous, while those with longer chains are

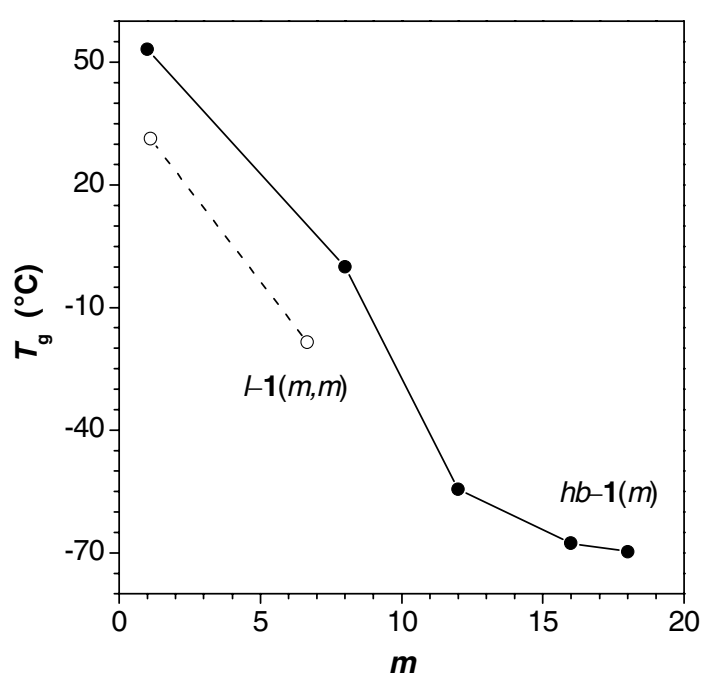

Fig. 6. Change of glass transition temperature $\left(T_{\mathrm{g}}\right)$ with number of carbon atoms of alkyl chains $(m)$ in the hyperbranched poly $\left[1,1^{\prime}\right.$ ferrocenylene( $n$-alkyl)silyne]s $[h b-\mathbf{1}(m)]$. The data for linear poly $\left[1,1^{\prime}\right.$-ferrocenylene(di- $n$-alkyl)silene]s $[l-\mathbf{1}(m, m)]$ are shown for comparison [36].

Table II. Thermal Properties of Hyperbranched Poly(ferrocenylenesilyne)s ${ }^{a}$

\begin{tabular}{lllccc}
\hline No. & $R$ in $-\left[\mathrm{Fc}_{3 / 2}(R) \mathrm{Si}_{n}-\right.$ & Polymer & $T_{\mathrm{g}}\left({ }^{\circ} \mathrm{C}\right)$ & $T_{\mathrm{m}}\left({ }^{\circ} \mathrm{C}\right)$ & $\Delta H\left(\mathrm{kcal}^{\mathrm{mol}}{ }^{-1}\right)$ \\
\hline 1 & $\mathrm{CH}_{3}$ & $h b-\mathbf{1}(1)$ & 53.1 & & \\
2 & $\mathrm{CH}=\mathrm{CH}_{2}$ & $h b-\mathbf{1}(\mathrm{Vi})$ & 40.0 & & \\
3 & $n-\mathrm{C}_{8} \mathrm{H}_{17}$ & $h b-\mathbf{1}(8)$ & 0 & & \\
4 & $n-\mathrm{C}_{12} \mathrm{H}_{25}$ & $h b-\mathbf{1}(12)$ & -54.5 & -20.5 & 0.91 \\
5 & $n-\mathrm{C}_{16} \mathrm{H}_{33}$ & $h b-\mathbf{1}(16)$ & -67.7 & -13.8 & 1.15 \\
6 & $n-\mathrm{C}_{18} \mathrm{H}_{37}$ & $h b-\mathbf{1}(18)$ & -69.7 & -36.7 & 7.76 \\
\hline
\end{tabular}

${ }^{a}$ Measured under nitrogen by DSC. Fc $=1,1^{\prime}$-ferrocenylene. 


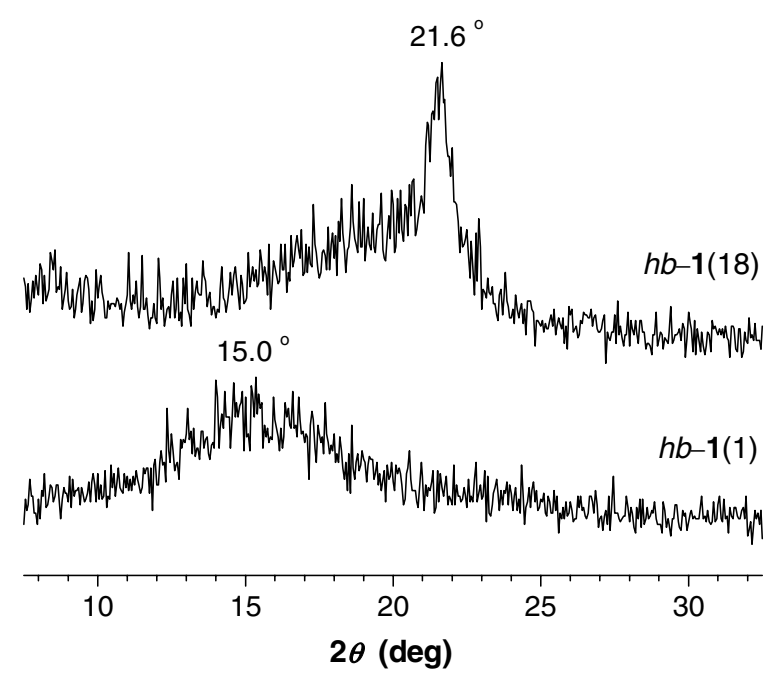

Fig. 7. XRD diagrams of hyperbranched poly $\left[1,1^{\prime}\right.$-ferrocenylene(n-octadecyl)silyne $] \quad[h b-1(18)] \quad$ and $\quad$ poly[1, $1^{\prime}$-ferrocenylene(methyl)silyne] [hb-1(1)].

semicrystalline. This can be further verified by powder X-ray diffraction (XRD) analyses. Figure 7 shows the XRD diagrams of $h b-\mathbf{1}(1)$ and $h b-\mathbf{1}(18)$. Polymer $h b$-1(1) exhibits no peaks but a defuse halo with its maximum at a $2 \theta$ angle of $\sim 15^{\circ}$, which is similar to that of its linear counterpart $l-\mathbf{1}(1,1)$ $\left(2 \theta \sim 14^{\circ}\right)$ [38]. Polymer $h b-1(18)$, on the other hand, exhibits a narrow diffraction peak at $2 \theta \sim 21.6^{\circ}$. Although the peak is not so sharp due to the imperfect packing of the alkyl chains in the nanocrystallites, an average grain size of $\sim 15 \mathrm{~nm}$ is calculated using the Scherrer equation $[19,39,40]$.

\section{PYROLYTIC CERAMIZATION}

The linear poly(ferrocenylenesilene)s have been utilized as polymer precursors to ceramics [27,41]. Will the hyperbranched poly(ferrocenylene)s play the same role? - The answer to this question is a firm "yes". Investigations of thermolysis behaviors by thermogravimetric analysis (TGA) reveal that most of the hyperbranched polymers are thermally stable, losing little of their weights when heated to $\sim 350$ $400^{\circ} \mathrm{C}$ (Fig. 8). The polymers undergo a rapid thermolytic degradation in the temperature region of $\sim 400-550^{\circ} \mathrm{C}$, after which, the TGA curves are almost leveled off. Little further weight losses are recorded when the polymers are further heated to $\sim 680^{\circ} \mathrm{C}$, indicating that the polymers have been ceramized by pyrolyses. The ceramization yields of

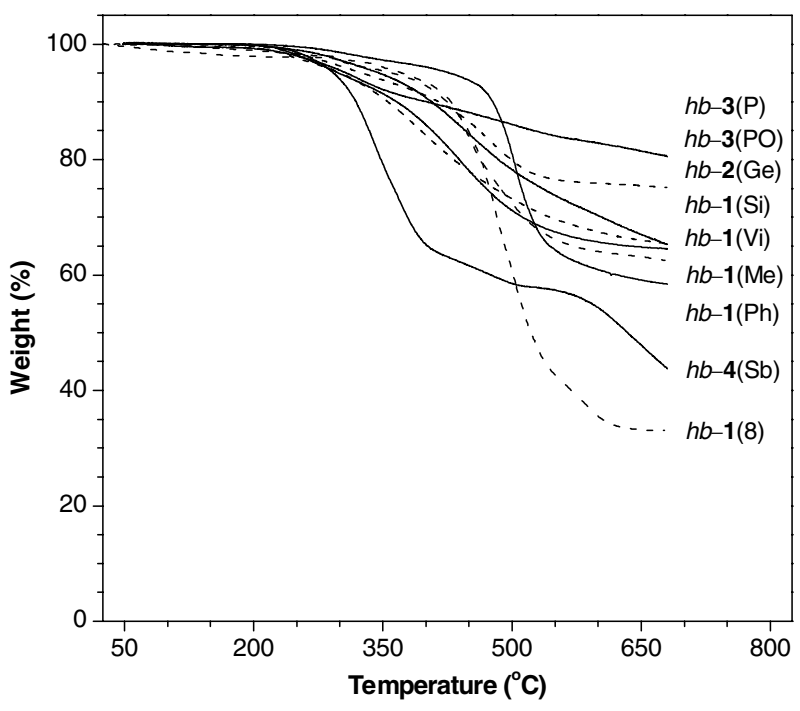

Fig. 8. TGA thermograms of hyperbranched poly(ferrocenylene)s measured under nitrogen at a heating rate of $20^{\circ} \mathrm{C} / \mathrm{min}$.

the Si-containing hyperbranched polymers at this temperature are $>60 \mathrm{wt} \%$, which is much higher than that of their linear congeners $l-1(1,1)$ or $l$ $\mathbf{1}(\mathrm{Ph}, \mathrm{Ph})$ under the comparable pyrolysis conditions (36 and $17 \mathrm{wt} \%$, respectively) [41]. The ceramization yields of the P-containing hyperbranched polymers $h b-3(\mathrm{P})$ and $h b-3(\mathrm{PO})$ are as high as $\sim 80 \mathrm{wt} \%$. These high yields can be attributed to the high thermal stability of the hyperbranched polymer frameworks and to the better retention of the pyrolysis-generated species inside the three-dimensional macromolecular structures.

The hyperbranched poly(ferrocenylenesilyne)s with long $n$-alkyl chains $[h b-1(8-18)]$ show different pyrolysis behaviors. The TGA thermogram of $h b-\mathbf{1}(8)$ is given in Fig. 8 as an example. The polymer starts to lose its weight at a temperatures similar to that of $h b$ 1(1) but gives ceramic product in a much lower yield $\left(\sim 33 \mathrm{wt} \%\right.$ at $\left.680^{\circ} \mathrm{C}\right)$. A further increase in the alkyl chain length leads to a further decrease in the ceramization yield. For example, from the pyrolysis of $h b-1(18)$ at $\sim 690^{\circ} \mathrm{C}$, a ceramic product is obtained in a yield as low as $\sim 24 \mathrm{wt} \%$. Apparently the long alkyl chains are detrimental to ceramization of the hyperbranched polymers.

The TGA analyses have clearly shown that the hyperbranched polymers without long alkyl chains are promising candidates for precursors to ceramics. It is thus worthy of further studying and exploring their ceramic transformations. Heating the polymers 
to high temperatures $\left(700-1200^{\circ} \mathrm{C}\right.$, normally $1000^{\circ} \mathrm{C}$ ) and then isothermally sintering them in an inert gas, typically nitrogen, atmosphere affords ceramic products in up to $\sim 69 \mathrm{wt} \%$ yields (Table III). Scanning electron microscopy (SEM) of ceramic $c-1(1) *$ (calcinated at $1200^{\circ} \mathrm{C}$ under argon) reveals its mesoporous morphology comprising of many tortuously interconnected clusters with sizes of a few hundred nanometers (Fig. 9a). This morphological structure suggests that the pyrolytic decomposition first strips off some of the organic moieties from the skeletons of the hyperbranched polymer spheres and the following fast evaporation of the volatile fragments at the high temperatures leaves behind the mesoscopic pores. In the meantime, the naked reactive inorganic residues undergo heavy cross-linking reactions to aggregate into the nanoscopic clusters.

Ceramic $c-\mathbf{1}(\mathrm{Ph})$ prepared by pyrolysis of $h b$ $\mathbf{1}(\mathrm{Ph})$ at $1000^{\circ} \mathrm{C}$ under nitrogen is also mesoporous, as can be seen from its side view shown in Fig. 9 b. Ceramic $c-\mathbf{2}(\mathrm{Ge})$ shows an interesting network structure consisting of micrometer-sized holes and channels with smooth surfaces, much like a "Swiss cheese" (Fig. 9c). Considerable amounts of organic volatiles may have evaporated during the pyrolysis process, leaving behind this sponge-like morphologic structure. Fusing of the inorganic species at the high temperatures, on the other hand, may have sleeked up the surfaces. The morphologies of ceramics $c-3(\mathrm{P})$, $c-3(\mathrm{PO})$ and $c-\mathbf{4}(\mathrm{Sb})$ share one common structural feature: their surfaces are all decorated with nanoand microclusters. The associative agglomeration of the inorganic species in the bulk and their segregating crystallization at the interface may be the causes for the formations of the big lumps and the small clusters, respectively.

\section{CERAMIC COMPOSITIONS}

$\mathrm{X}$-ray photoelectron spectroscopy (XPS) is a power tool for estimating surface compositions. XPS analyses reveal that the ceramics obtained from the pyrolyses of the hyperbranched poly(ferrocenylene)s contain the expected carbon and iron atoms as well as the respective elements of group 14 or 15 (Table IV). The surfaces of the ceramics are mainly comprised of carbon (up to $\sim 87$ atom $\%$ ) with some small amounts of iron (0.6-9.8 atom \%) and group 14 or 15 element (0.6-16.1 atom \%). A considerable amount of oxygen (up to $\sim 37$ atom \%) is detected on the surface. Oxygenic species have often been found in the ceramic products prepared by the polymer precursor routes, although the pyrolyses have been conducted in sealed quartz tubes under inert-gas atmosphere or in tube furnaces under nitrogen steam [42,43]. As the polymer precursors, except for $h b-3(\mathrm{PO})$, do not contain oxygen, the oxygenic species may thus be introduced by moisture absorbed by the polymer samples prior to pyrolyses and/or by postoxidation of the ceramics during the handling and storage processes.

The Fe2p core level photoelectron spectra reveal two sets of $\mathrm{Fe} 2 \mathrm{p}_{1 / 2}$ and $\mathrm{Fe} 2 \mathrm{p}_{3 / 2}$ split peaks (Fig. 10), which can be assigned to $\mathrm{Fe}(720$ and $707 \mathrm{eV})$ and $\mathrm{Fe}_{2} \mathrm{O}_{3}$ species (725.3 and $\left.711.4 \mathrm{eV}\right)[44,45]$. The ratio of the two species varies in different ceramics. The $\mathrm{Si}$ - and $\mathrm{Sb}$-containing ceramics contain almost exclusively $\mathrm{Fe}_{2} \mathrm{O}_{3}$ species, whereas the Ge- and P-containing ceramics contain both of the two species. The peaks associated with the Fe species are noticeably high in the spectra of ceramics $c-3(\mathrm{P})$ and $c-3(\mathrm{PO})$. Additionally, for most of the Si-containing ceramics,

Table III. Pyrolytic Ceramization of Hyperbranched Poly(ferrocenylene)s

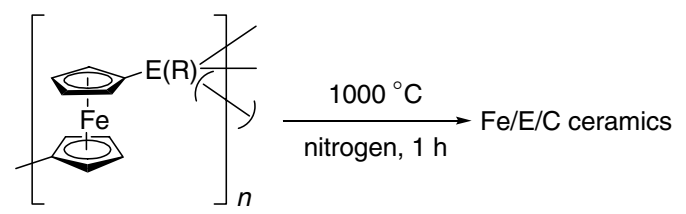

\begin{tabular}{|c|c|c|c|c|c|}
\hline $\mathrm{E}(\mathrm{R})$ & Ceramic & Yield (wt\%) & $\mathrm{E}$ & Ceramic & Yield (wt\%) \\
\hline $\mathrm{SiCH}_{3}$ & $c-1(1)$ & 50.0 & $\mathrm{Si}$ & $c-1(\mathrm{Si})$ & 60.4 \\
\hline $\mathrm{Si}\left(\mathrm{CH}=\mathrm{CH}_{2}\right)$ & $c-1(\mathrm{Vi})$ & 50.0 & $\mathrm{Ge}$ & $c-2(\mathrm{Ge})$ & 40.6 \\
\hline \multirow[t]{3}{*}{$\mathrm{SiC}_{6} \mathrm{H}_{5}$} & $c-1(\mathrm{Ph})$ & 57.4 & $\mathrm{P}$ & $c-3(\mathrm{P})$ & 68.8 \\
\hline & & & $\mathrm{PO}$ & $c-3(\mathrm{PO})$ & 62.5 \\
\hline & & & $\mathrm{Sb}$ & $c-4(\mathrm{Sb})$ & 25.2 \\
\hline
\end{tabular}



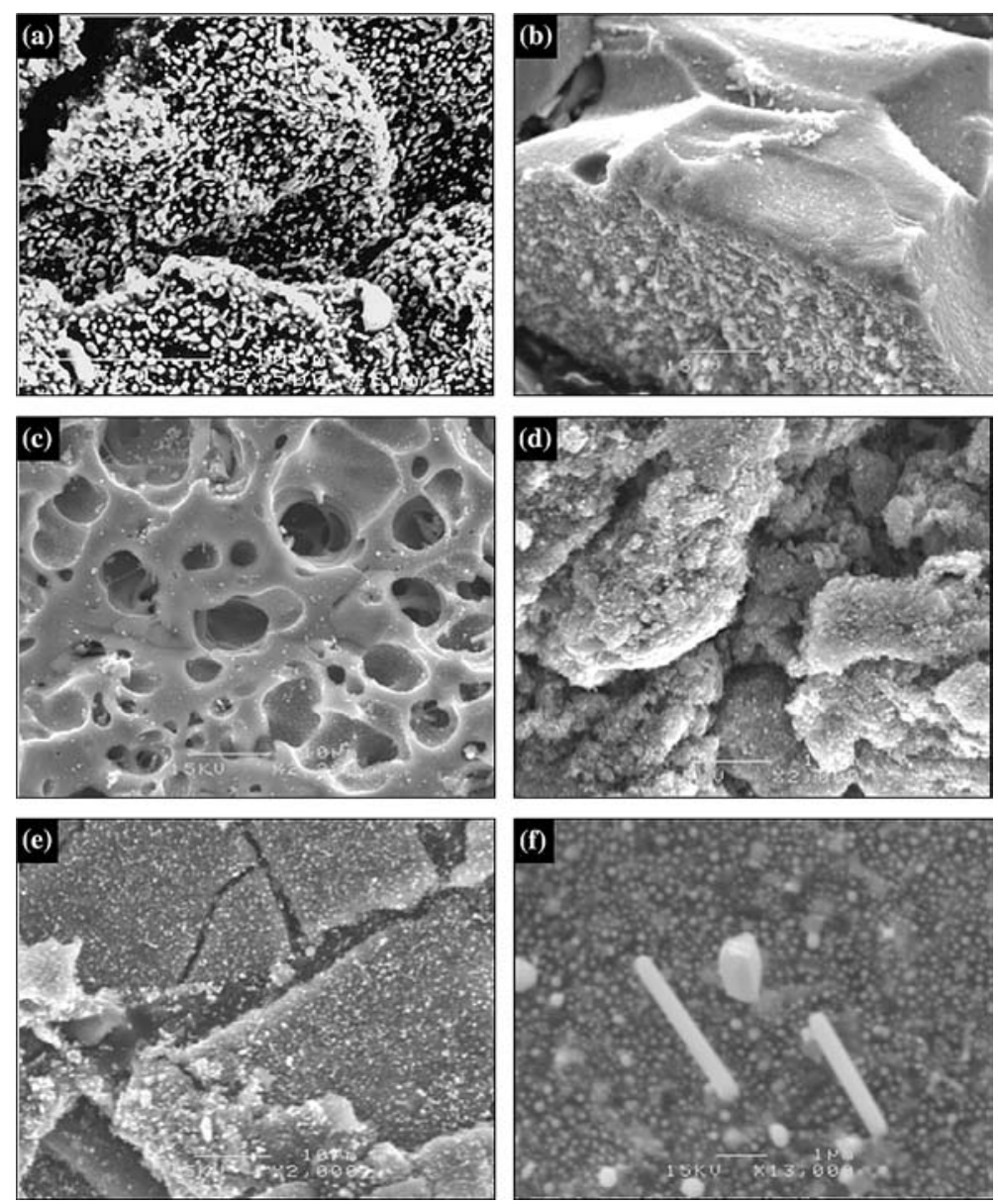

Fig. 9. SEM photomicrographs of ceramics prepared by pyrolyses of (a) $h b-\mathbf{1}(1)$ at $1200^{\circ} \mathrm{C}$ under $\operatorname{argon}\left[c-1(1)^{*}\right]$ and $($ b) $h b-\mathbf{1}(\mathrm{Ph})$, (c) $h b-\mathbf{2}(\mathrm{Ge}),(\mathrm{d}) \mathrm{hb}-\mathbf{3}(\mathrm{P}),(\mathrm{e}) h b-\mathbf{3}(\mathrm{PO})$, and (f) $h b-\mathbf{4}(\mathrm{Sb})$ at $1000^{\circ} \mathrm{C}$ under nitrogen.

Table IV. Ceramic Compositions

\begin{tabular}{|c|c|c|c|c|c|c|c|c|c|c|}
\hline \multirow[t]{2}{*}{ No. } & \multirow[t]{2}{*}{ Ceramic $^{a}$} & \multicolumn{5}{|c|}{ XPS (atom \%) } & \multicolumn{4}{|c|}{ EDX (atom \%) } \\
\hline & & $\mathrm{C}$ & $\mathrm{N}$ & $\mathrm{O}$ & $\mathrm{E}$ & $\mathrm{Fe}$ & $\mathrm{C}$ & $\mathrm{O}$ & $\mathrm{E}$ & $\mathrm{Fe}$ \\
\hline 1 & $c-1(1)$ & 78.0 & 0 & 15.2 & 0.7 & 6.1 & 30.2 & 9.4 & 24.4 & 36.0 \\
\hline 2 & $c-1(1)^{*}$ & 86.7 & 0 & 8.9 & 0.6 & 3.8 & 22.4 & 5.3 & 29.1 & 43.2 \\
\hline 3 & $c-1(\mathrm{Vi})$ & 71.0 & 1.8 & 18.0 & 7.8 & 1.4 & 68.3 & 18.5 & 5.8 & 7.4 \\
\hline 4 & $c-1(\mathrm{Ph})$ & 81.2 & 2.6 & 10.5 & 4.8 & 0.9 & 77.3 & 10.3 & 4.3 & 8.0 \\
\hline 5 & $c-1(\mathrm{Si})$ & 45.0 & 0.6 & 36.7 & 16.1 & 1.6 & 45.2 & 38.2 & 12.7 & 3.9 \\
\hline 6 & $c-2(\mathrm{Ge})$ & 78.7 & 0 & 16.7 & 1.5 & 3.1 & 69.0 & 15.4 & 10.2 & 5.4 \\
\hline 7 & $c-3(\mathrm{P})$ & 86.4 & 0 & 10.1 & 2.6 & 0.9 & 77.4 & 14.4 & 3.4 & 4.8 \\
\hline 8 & $c-3(\mathrm{PO})$ & 83.5 & 0 & 13.1 & 2.6 & 0.6 & 76.9 & 12.4 & 4.4 & 6.3 \\
\hline 9 & $c-4(\mathrm{Sb})$ & 59.3 & 0.1 & 27.3 & 3.5 & 9.8 & 68.3 & 17.4 & 8.1 & 6.2 \\
\hline
\end{tabular}

${ }^{a}$ All ceramics were fabricated by pyrolysis at $1000^{\circ} \mathrm{C}$ under nitrogen, except for ceramic $c-1(1)^{*}$, which was made by calcination at $1200^{\circ} \mathrm{C}$ under argon.

small amounts of nitrogenic species (up to 2.6 atom\%) have been detected. It has been reported that amorphous $\mathrm{Si}_{3} \mathrm{~N}_{4}, \mathrm{Fe}_{2} \mathrm{~N}$ and $\mathrm{Fe}_{4} \mathrm{~N}$ species have been formed in the ceramization processes of the linear poly(ferrocenylenesilene)s due to the incorporation of nitrogen from the pyrolysis atmosphere into the 


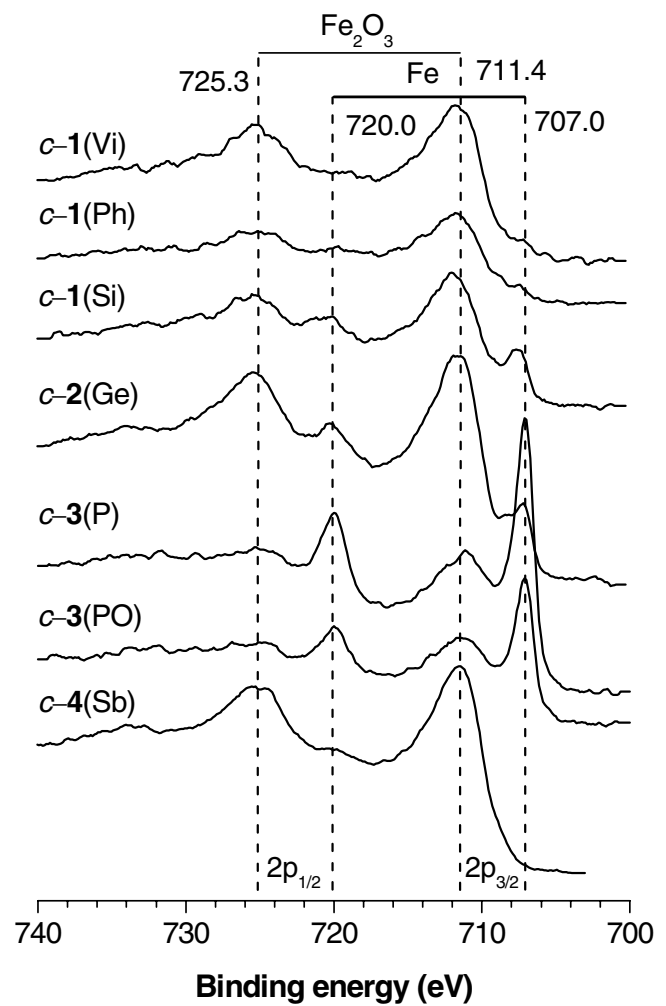

Fig. 10. $\mathrm{Fe} 2 \mathrm{p}$ photoelectron spectra of ceramics prepared by pyrolyses of poly(ferrocenylene)s at $1000^{\circ} \mathrm{C}$ under nitrogen. Spectra calibrated to the position of $\mathrm{C} 1 \mathrm{~s}$ peak at $284.8 \mathrm{eV}$ [44].

ceramic products [46]. Although no diffraction peaks associated with the nitrogenic species can be observed in the XRD analyses (vide infra), absorption peaks of the nitrogen and silicon species at 398.0 and $102.5 \mathrm{eV}$ in the N1s and Si2p core level spectra of $c-\mathbf{1}(\mathrm{Ph})$, respectively, suggest the incorporation of nitrogen as a nitride species in the ceramic product (Fig. 11) [46].

Bulk compositions of the ceramics are analyzed by energy-dispersion X-ray (EDX) spectroscopy. As can be seen from the data listed in Table IV, compared

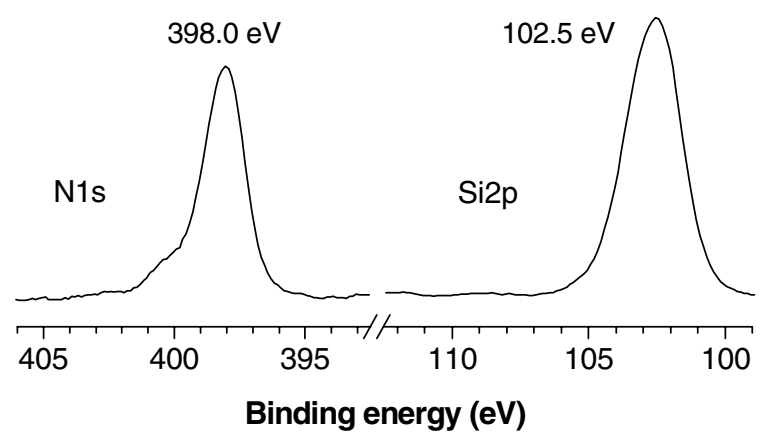

Fig. 11. N1s and $\mathrm{Si} 2 \mathrm{p}$ photoelectron spectra of ceramic $c-1(\mathrm{Ph})$ calibrated to the position of $\mathrm{C} 1 \mathrm{~s}$ peak at $284.8 \mathrm{eV}$ [44]. to the values obtained from the XPS surface analyses, the contents of $\mathrm{C}$ and $\mathrm{O}$ in the bulk generally decrease, whereas the amounts of $\mathrm{Fe}$ as well as those of the elements of groups 14 and 15 generally increase. No nitrogenic species are detected at all in the bulk of the ceramics. This gradient distribution from bulk to surface suggests that the ceramization process starts from pyrolysis-induced formation and aggregation of metallic species inside the organic matrix. The ceramics may thus be imagined as metal inner cores covered by carbonic and oxide outer mantles.

To gain more information on the compositional species in the ceramic materials, XRD patterns of the ceramics are measured. Although the hyperbranched polymer precursors are amorphous in nature (cf., Fig. 7), their ceramic products exhibit well-defined XRD patterns. The Bragg reflection peaks are identified according to the database files of the Joint Committee on Powder Diffraction Standards of the International Center for Diffraction Data (JCPDS-ICDD). All of the Si-containing ceramics display the diffraction patterns characteristic of $\alpha-\mathrm{Fe}$ and carbon steel (Fe, C; Fig. 12). The presence of the later is rather unusual, as its $h k l$ values suggest a face-centered-cubic (fcc) phase of $\gamma$-Fe at room temperature. While $\alpha$-Fe is stable and crystallizes in a body-centered-cubic (bcc) phase, $\gamma$-Fe is normally unstable and has not been found in the ceramics prepared from the pyrolyses of the linear poly(ferrocenylenesilene)s [46]. Recently, however, stable $\gamma-\mathrm{Fe}$ has been found inside carbon nanotubes [47]. It is possible that the carbonic nanostructures have helped stabilize the $\gamma$-Fe phase in the ceramics. More detailed studies are underway in our laboratories to clarify the appearance of this unusual phase in the ceramic products.

No peaks associated with $\mathrm{Fe}_{2} \mathrm{O}_{3}$ can be identified, suggesting that $\mathrm{Fe}_{2} \mathrm{O}_{3}$ is present only as a thin surface layer (as found by XPS analyses) but not in the bulk of these ceramics. The sizes of the $\alpha-\mathrm{Fe}$ and $\mathrm{Fe}, \mathrm{C}$ crystallites are calculated by the Scherrer equation to be in the range of $15-25 \mathrm{~nm}$. The other ceramics show no peaks of elemental iron but iron alloys $\left(\beta-\mathrm{Fe}_{1.6} \mathrm{Ge}\right.$ and $\varepsilon$-SbFe) or iron phosphides $\left(\mathrm{FeP}\right.$ and $\left.\mathrm{Fe}_{2} \mathrm{P}\right)$. The crystal sizes of the $\mathrm{Ge}$ - and $\mathrm{Sb}-$ Fe alloys are 22 and $33 \mathrm{~nm}$, respectively, whereas the sizes of the iron phosphides are as small as $\sim 0.8 \mathrm{~nm}$. It is noteworthy that broad peaks at $2 \theta \sim 26^{\circ}$, identifiable as graphite, are observed only in the XRD patterns of the ceramics containing elemental iron, suggesting that only Fe can efficiently catalyze graphite crystallization. 


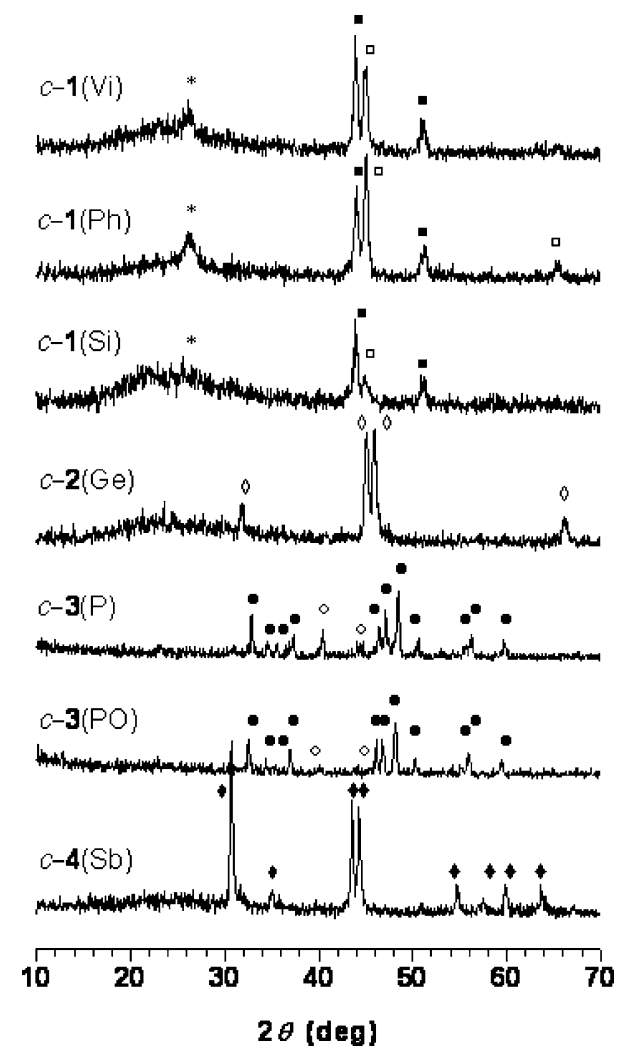

Fig. 12. XRD diffractograms of ceramics containing crystalline species of $(\square) \alpha$-Fe (JCPDS-ICDD file \#06-0696) (ロ) Fe,C (\#310619), $(\diamond) \beta-\mathrm{Fe}_{1.6} \mathrm{Ge}(\# 18-0556),(\bigcirc) \mathrm{FeP}(\# 39-0809),(\bullet) \mathrm{Fe}_{2} \mathrm{P}$ (\#33-0670), ( ) $\varepsilon-\mathrm{SbFe}(\# 34-1053)$, and (*) graphite (\#26-1080).

The ceramics obtained from the pyrolyses of $h b-\mathbf{1}(1)$ at $700\left[c-1(1)^{* *}\right]$ and $1200^{\circ} \mathrm{C}\left[c-1(1)^{*}\right]$ show different Bragg reflections (Fig. 13). The ceramics prepared at the lower temperature exhibit weaker and broader peaks of smaller crystallites $(\sim 7-9 \mathrm{~nm}$ in size), while those prepared at the higher temperature exhibit much sharper and well defined diffraction peaks of iron species, especially iron silicide $\left(\mathrm{Fe}_{3} \mathrm{Si}\right)$. The sizes of the crystallites are in the range of $\sim 37-60 \mathrm{~nm}$, much bigger then those obtained at the lower temperature. Obviously the calcination at the higher temperature favors the crystallites to grow into bigger sizes.

The structures of the nanocrystallites in the ceramics are studied by high-resolution transmission electron microscopy (HRTEM), examples of which are given in Fig. 14. The shapes and sizes of the inorganic nanoparticles vary in different ceramics. Most $\mathrm{Fe}$ particles in $c-\mathbf{1}(\mathrm{Ph})$ take irregular round shapes (Fig. 14, image A1). The nanoparticles in c-2(Ge) look like Chinese dumplings (Fig. 14, image B1), with the darker core of metal alloy intimately

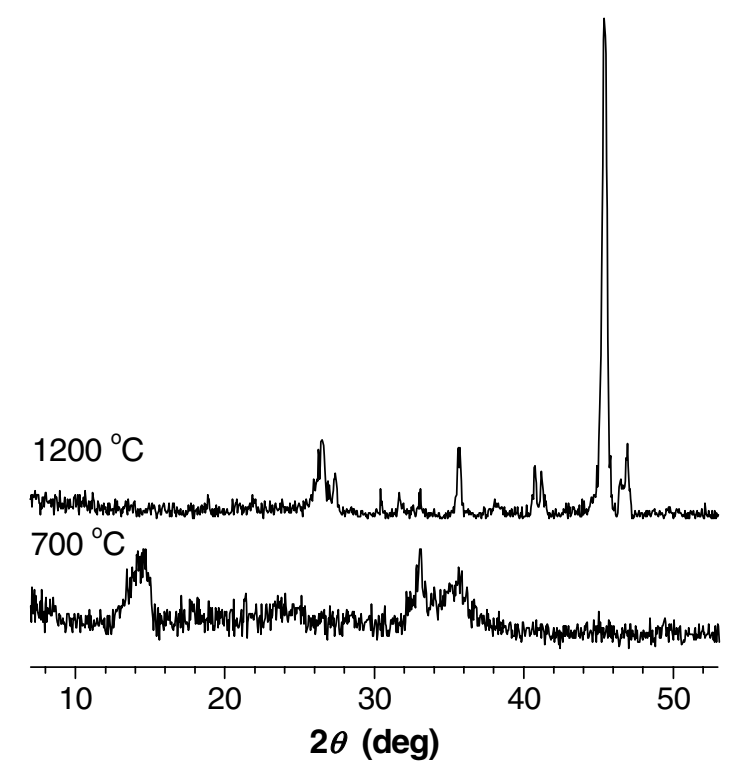

Fig. 13. XRD diffractograms of ceramics prepared by pyrolyses of $h b-\mathbf{1}(1)$ at $700\left[c-1(1)^{* *}\right]$ and $1200^{\circ} \mathrm{C}\left[c-1(1)^{*}\right]$ under argon.

surrounded by the lighter shell of carboneous species, as clearly shown by image B2. For ceramic $c-\mathbf{4}(\mathrm{Sb})$, it is difficult to identify isolated particles because most of them are clustered together in the amorphous environment (images $\mathrm{C} 1$ and $\mathrm{C} 2$ ). These findings confirm that $\mathrm{Ge}$ and $\mathrm{Sb}$ readily form alloys with Fe.

$\mathrm{Fe}$ is known to catalyze the crystallization of graphite and the formation of nanotubes. From the HRTEM images of $c-\mathbf{1}(\mathrm{Ph})$, graphite can be easily identified with a lattice spacing of $3.4 \AA$. The Fe nanocrystals are covered by the graphite sheets (Fig. 14A2), which may have acted as protective coating toward oxidation of the nanoparticles. In addition, small, empty nanotube-like structures are clearly seen in the HRTEM images and their diffraction patterns of selected area (Fig. 14A3). Different from ceramic $c-\mathbf{1}(\mathrm{Ph})$, ceramics $c-\mathbf{2}(\mathrm{Ge})$ and $c-\mathbf{4}(\mathrm{Sb})$ exhibit no images and diffraction patterns related to the graphite layers, in accordance with the powder XRD observations discussed above (cf., Fig. 12).

\section{MAGNETIC SUSCEPTIBILITIES}

Because the ceramic materials contain nanoscopic iron species, they are expected to be magnetically active. Indeed, all the ceramic products are 

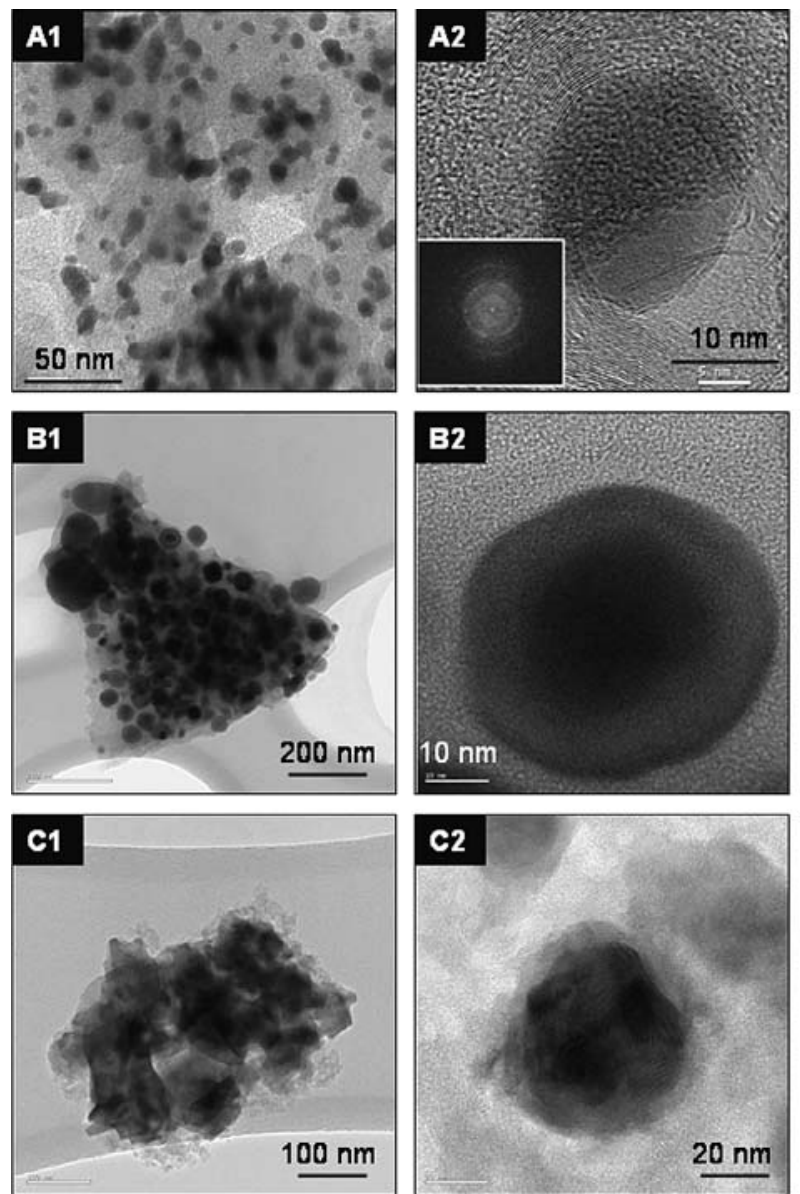
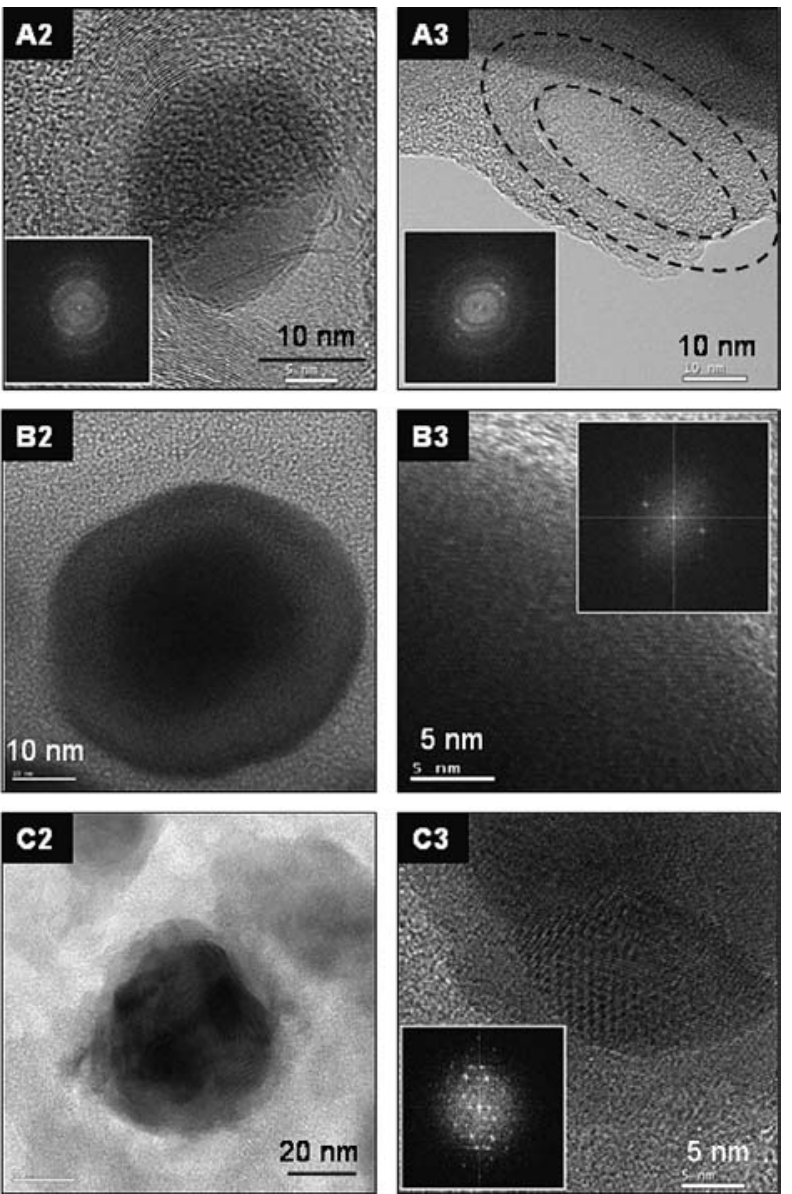

Fig. 14. TEM images of ceramics (A) $c-\mathbf{1}(\mathrm{Ph}),(\mathrm{B}) c-\mathbf{2}(\mathrm{Ge})$ and $(\mathrm{C}) c-\mathbf{4}(\mathrm{Sb})$.

attracted to a bar magnet at room temperature; that is, they are readily magnetizable. The magnetization behaviors of the ceramics are thus studied using vibrating sample magnetometer (VSM) and superconducting quantum interference device (SQUID) techniques.

Ceramic $c-\mathbf{1}(1)^{*}$, prepared by pyrolysis of $h b-\mathbf{1}(1)$ at $1200^{\circ} \mathrm{C}$ under argon, is swiftly magnetized at $300 \mathrm{~K}$, as evidenced by an immediate raise in magnetization upon its exposure to a magnetic field (Fig. 15). Its magnetization rapidly increases with an increase in the strength of the applied field and becomes saturated at $\sim 49 \mathrm{emu} / \mathrm{g}$ when the external field reaches $\sim 5 \mathrm{kOe}$. Its magnetic saturation $\left(M_{\mathrm{s}}\right)$ is further enhanced at low temperature $(5 \mathrm{~K})$ to $\sim 51 \mathrm{emu} / \mathrm{g}$, close to the value for bulk maghemite $(74 \mathrm{emu} / \mathrm{g})$ [48]. As shown in the inset of Fig. 15, even at a high magnification, no hysteresis loops can be seen in the magnetization plots: the magnetic remanence $\left(M_{\mathrm{r}}\right)$ and coercivity $\left(H_{\mathrm{c}}\right)$ of $c-\mathbf{1}(1) *$ are practically zero.

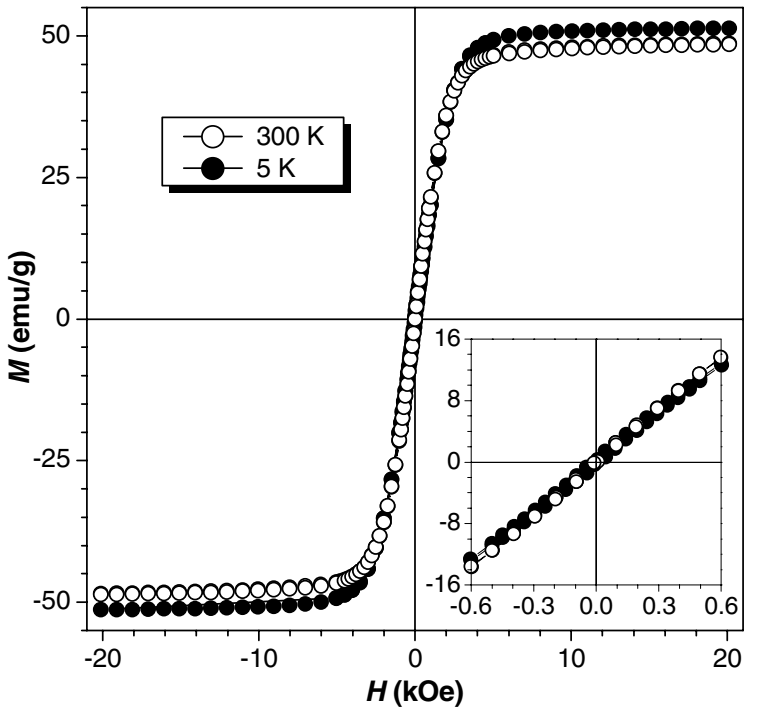

Fig. 15. Plots of magnetization $(M)$ versus applied magnetic field $(H)$ at 300 and $5 \mathrm{~K}$ for ceramic $c-1(1)^{*}$ prepared by pyrolysis at $1200^{\circ} \mathrm{C}$ under argon. Inset (lower right panel): enlarged portion of the plots in the low magnetic field region. 
The ceramics prepared from the hyperbranched poly(ferrocene) precursors at $1000^{\circ} \mathrm{C}$ under nitrogen show different magnetization behaviors. All the magnetization plots contain hysteresis loops, as can be seen from the inset of Fig. 16. Among the four metalloid species, the Ge-containing ceramic $c-2(\mathrm{Ge})$ shows the best performance: its $M_{\mathrm{s}}$ value is high $(21 \mathrm{emu} / \mathrm{g})$ and its hysteresis loop is narrow (with an $H_{\mathrm{c}}$ value as small as $\sim 0.07 \mathrm{kOe}$; Table $\mathrm{V}$, No. 6). The Si- and Sb-containing ceramics exhibit $M_{\mathrm{s}}$ values of 11-19 and $9 \mathrm{emu} / \mathrm{g}$, respectively. The magnetic susceptibilities of the P-containing ceramics are very weak. The reason for this might be due to the ionic iron phosphide species and/or their small crystallite sizes $(\sim 0.8 \mathrm{~nm})$ as revealed by the XRD analyses (cf., Fig. 12).

It should be stressed that the majority of the magnetoceramics prepared from the pyrolyses of the hyperbranched poly(ferrocene) precursors display very low $H_{\mathrm{c}}$ values: many of them are lower than $0.1 \mathrm{kOe}$ and some of them are as low as $0.06 \mathrm{kOe}$. A ferromagnetic material with a coercivity smaller than $0.126 \mathrm{kOe}$ (or $10^{4} \mathrm{~A} / \mathrm{m}$ ) is termed a soft magnet $[49,50]$. Most of the magnetoceramics prepared in this work are thus soft magnetic materials. The high magnetizability of $c-1(1)^{*}$ coupled with its practically zero coercivity makes it an excellent soft ferromagnetic material, which

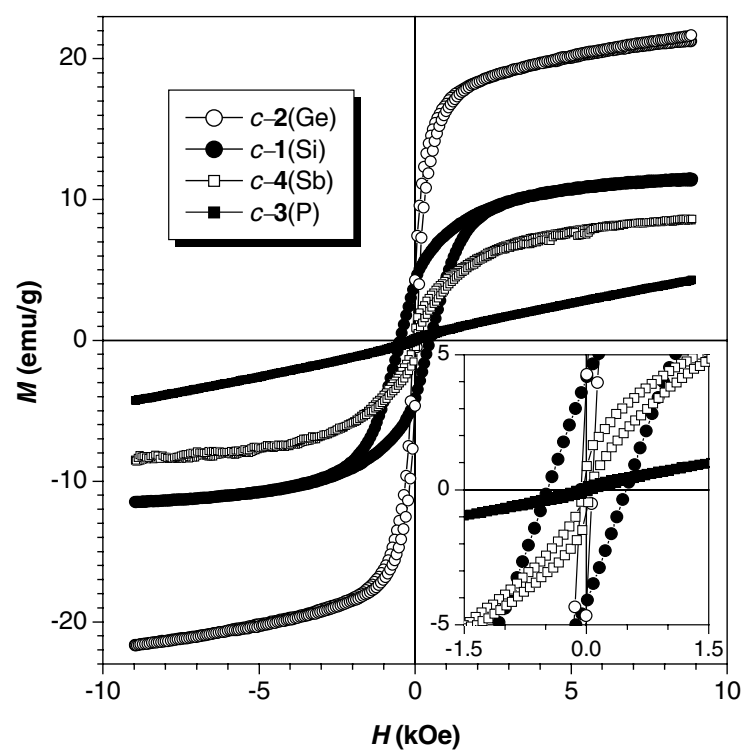

Fig. 16. Plots of magnetization $(M)$ versus applied magnetic field $(H)$ at $300 \mathrm{~K}$ for ceramics $c-\mathbf{1}(\mathrm{Si}), c-\mathbf{2}(\mathrm{Ge}), c-\mathbf{3}(\mathrm{P})$ and $c-\mathbf{4}(\mathrm{Sb})$. Inset (lower right panel): enlarged portion of the plots in the low magnetic field region.
Table V. Magnetic Properties ${ }^{a}$ of Ceramics $^{b}$

\begin{tabular}{lllll}
\hline No. & Ceramic $^{b}$ & $M_{\mathrm{s}}(\mathrm{emu} / \mathrm{g})$ & $M_{\mathrm{r}}(\mathrm{emu} / \mathrm{g})$ & $H_{\mathrm{c}}(\mathrm{kOe})$ \\
\hline 1 & $c-\mathbf{1}(1)$ & $16(21)^{c}$ & $2.6(6.4)^{c}$ & $0.65(0.18)^{c}$ \\
2 & $c-\mathbf{1}(1)^{*}$ & $49(51)^{c}$ & $\sim 0(\sim 0)^{c}$ & $\sim 0(\sim 0)^{c}$ \\
3 & $c-\mathbf{1}(\mathrm{Vi})$ & 14 & 1.5 & 0.06 \\
4 & $c-\mathbf{1}(\mathrm{Ph})$ & 19 & 4.0 & 0.39 \\
5 & $c-\mathbf{1}(\mathrm{Si})$ & 11 & 4.2 & 0.44 \\
6 & $c-\mathbf{2}(\mathrm{Ge})$ & 21 & 4.2 & 0.07 \\
7 & $c-\mathbf{3}(\mathrm{P})$ & 5 & 0.1 & 0.09 \\
8 & $c-3(\mathrm{PO})$ & $<1$ & $\sim 0$ & 0.08 \\
9 & $c-\mathbf{4}(\mathrm{Sb})$ & 9 & 0.8 & 0.06 \\
\hline
\end{tabular}

${ }^{a}$ Determined by VSM unless otherwise specified.

Abbreviations: $M_{\mathrm{s}}=$ saturation magnetization (in an external field of $\sim 10 \mathrm{kOe}$ ), $M_{\mathrm{r}}=$ magnetic remanence (at zero external field), and $H_{\mathrm{c}}=$ coercivity (at zero magnetization).

${ }^{b}$ All the ceramics were fabricated by pyrolysis at $1000^{\circ} \mathrm{C}$ under nitrogen, except for $c-1(1)^{*}$, which was prepared at $1200^{\circ} \mathrm{C}$ under argon.

${ }^{c}$ Determined by SQUID at $300 \mathrm{~K}$ (values in parentheses at $5 \mathrm{~K}$ ).

may find many applications in various electromagnetic systems.

\section{CONCLUSIONS}

In this account, we have briefly summarized our earlier work as well as our recent results on the syntheses of hyperbranched poly(ferrocene)s containing groups 14 and 15 elements and their utilities as precursors for the fabrications of advanced functional ceramic materials. The ferrocene and metalloid moieties are readily fused into threedimensional macromolecular structures by a onepot synthetic protocol in good isolation yields. The properties of the hyperbranched polymers vary with the molecular structures of the metalloid monomers. Whilst the polymers containing no or short alkyl chains $(R)$ are insoluble or partially soluble, those with long alkyl chains are completely soluble in common organic solvents. The soluble hyperbranched poly(ferrocenylenesilyne)s are electronically conjugated with their absorption band edges entering the infrared region, probably due to an extended $\sigma-\pi$ conjugation in the three-dimensional macromolecular spheres. Furthermore, the hyperbranched polymers are excellent precursors to Fe-containing ceramics, thanks to their good retention of pyrolytically generated inorganic species. The pyrolysis temperature and atmosphere clearly affect the properties of the resultant ceramic materials. While ceramization at $700^{\circ} \mathrm{C}$ furnishes only small crystallites, an increase in temperature to $1200^{\circ} \mathrm{C}$ 
results in bigger iron nanoclusters with higher magnetic susceptibilities. The pyrolyses at $1000^{\circ} \mathrm{C}$ under nitrogen transform the Si-containing polymer precursors into ceramics containing elemental iron species. On the other hand, the Ge- and Sbcontaining polymers are converted into ceramics with respective Fe-E alloys, and the P-containing polymers are changed to ceramics with iron phosphides. Changing the sintering atmosphere to argon produces the ceramic containing big crystals of iron silicide $\left(\mathrm{Fe}_{3} \mathrm{Si}\right)$, which is magnetically highly susceptible and practically hysteresis-free. This ceramic is thus an excellent soft ferromagnetic material with a high potential of finding high-tech applications.

\section{ACKNOWLEDGMENTS}

We thank the financial supports of the Hong Kong Research Grants Council (Project Nos.: HKUST 6121/01P, 6085/02P, 604903, and 603304) and the University Grants Committee of Hong Kong through an Area of Excellence Scheme (Project No. AoE/P-10/01-1-A). We also thank the technical assistance and helpful discussions of the technical staffs in the Materials Characterization \& Preparation Facility of our University.

\section{REFERENCES}

1. H. Shirakawa, Angew. Chem. Int. Ed. 40, 2575 (2001).

2. A. G. MacDiarmid, Angew. Chem. Int. Ed. 40, 2581 (2001).

3. A. J. Heeger, Angew. Chem. Int. Ed. 40, 2591 (2001).

4. J. W. Y. Lam and B. Z. Tang, J. Polym. Sci. Part A: Polym. Chem, 40, 2607 (2003).

5. M. Häußler, J. W. Y. Lam, R. Zheng, H. Peng, J. Luo, J. Chen, C. C. W. Law, and B. Z. Tang, C. R. Chim. 6, 833 (2003).

6. M. Häußler, R. Zheng, J. W. Y. Lam, H. Tong, H. Dong, and B. Z. Tang, J. Phys. Chem. B. 108, 10645 (2004).

7. B. Z. Tang, Polym. News. 26, 262 (2001).

8. J. W. Y. Lam, H. Peng, M. Häußler, R. Zheng, and B. Z. Tang, Mol. Cryst. Liq. Cryst. 415, 305 (2004).

9. J. W. Y. Lam, J. Chen, C. C. W. Law, H. Peng, Z. Xie, K. K. L. Cheuk, H. S. Kwok, and B. Z. Tang, Macromol. Symp. 196, 289 (2003).

10. Z. Xie, H. Peng, J. W. Y. Lam, J. Chen, Y. Zheng, C. Qiu, H. S. Kwok, and B. Z. Tang, Macromol. Symp. 195, 179 (2003).

11. K. K. L. Cheuk, B. S. Li, and B. Z. Tang, Curr. Trends Polym. Sci. 7, 41 (2002).

12. J. W. Y. Lam, J. Luo, H. Peng, Z. Xie, K. Xu, Y. Dong, L. Cheng, C. Qiu, H. S. Kwok, and B. Z. Tang, Chin. J. Polym. Sci. 19, 585 (2001).

13. R. Zheng, H. Dong, H. Peng, J. W. Y. Lam, and B. Z. Tang, Macromolecules. 37, 5197 (2004).

14. C. C. W. Law, J. Chen, J. W. Y. Lam, H. Peng, and B. Z. Tang, J. Inorg. Organomet. Polym. 14, 39 (2004).
15. J. Chen, H. Peng, C. C. W. Law, Y. Dong, J. W. Y. Lam, I. D. Williams, and B. Z. Tang, Macromolecules. 36, 4319 (2003).

16. K. Xu, H. Peng, Q. Sun, Y. Dong, F. Salhi, J. Luo, J. Chen, Y. Huang, D. Zhang, Z. Xu, and B. Z. Tang, Macromolecules. 35, 5821 (2002).

17. H. Peng, H. L. Cheng, J. Luo, K. Xu, Q. Sun, Y. Dong, F. Salhi, P. P. S. Lee, J. Chen, and B. Z. Tang, Macromolecules. 35, 5349 (2002).

18. Q. Sun, K. Xu, H. Peng, R. Zheng, M. Häußler, and B. Z. Tang, Macromolecules. 36, 2309 (2003).

19. Q. Sun, Q., J. W. Y. Lam, K. Xu, H. Xu, J. A. P. Cha, P. C. L. Wong, G. Wen, X. Zhang, X. Jing, F. Wang, and B. Z. Tang, Chem Mater. 12, 2617 (2000).

20. Q. Sun, H. Peng, K. Xu, and B. Z. Tang, in Macromolecules Containing Metal- and Metal-like Elements, A. Abd-El-Aziz, C. Carraher, C. Pittman, J. Sheats, and M. Zeldin, M. eds. (Wiley, New York, 2004), Vol. 2, Chapt. 2.

21. B. Z. Tang, K. Xu, H. Peng, J. Luo, X. Zhang, Q. Sun, J. W. Y. Lam, and J. A. K. Cha, US Patent 6,759,502 (2004).

22. A. S. Abd-El-Aziz, Coord. Chem. Rev. 233--234, 177 (2002).

23. A. S. Abd-El-Aziz, Macromol. Rapid Commun. 23, 995 (2002).

24. T. Yamamoto, Synlett. 425, (2003).

25. I. Manners, Science. 294, 1664 (2001).

26. D. A. Foucher, B. Z. Tang, and I. Manners, J. Am. Chem. Soc. 114, 6246 (1992).

27. B. Z. Tang, R. Petersen, D. A. Foucher, A. Lough, N. Coombs, R. Sodhi, and I. Manners, J Chem Soc Chem Commun. 523, (1993).

28. P. Nguyen, P. Gomez-Elipe, and I. Manners, Chem. Rev. 99, 1515 (1999)

29. R. M. Silverstein and F. X. Webster, Spectrometric Identification of Organic Compounds (Wiley, 1998), Chapt. 3.

30. R. T. Bailey and E. R. Lippincott, Spectrochim. Acta. 21, 389 (1965).

31. M. Ginzburg, M. J. MacLachlan, S. M. Yang, N. Coombs, T. W. Coyle, N. P. Raju, J. E. Greedan, R. H. Herber, G. A. Ozin, and I. Manners, J. Am. Chem. Soc. 124, 2625 (2002).

32. P. A. Bianconi, F. C. Schilling, and T. W. Weidman, Macromolecules. 22, 1697 (1989)

33. H. Chen, J. W. Y. Lam, J. Luo, Y. Ho, B. Z. Tang, D. Zhu, M. Wong, and H. S. Kwok, Appl. Phys. Lett. 81, 574 (2002).

34. J. Luo, Z. Xie, J. W. Y. Lam, L. Cheng, H. Chen, C. Qiu, H. S. Kwok, X. Zhan, Y. Liu, D. Zhu, and B. Z. Tang, Chem. Commun. 1740, (2001).

35. B. Z. Tang, X. Zhan, G. Yu, P. P. S. Lee, Y. Liu, and D. Zhu, J. Mater. Chem. 11, 2874 (2001).

36. D. A. Foucher, R. Ziembinski, B. Z. Tang, P. M. Macdonald, J. Massey, C. R. Jaeger, G. J. Vancso, and I. Manners, Macromolecules. 26, 2878 (1993).

37. J. M. G. Cowie, Polymers: Chemistry \& Physics of Modern Materials (Blackie, London, 1991), Chapt. 16.

38. J. Rasburn, R. Petersen, T. Jahr, R. Rulkens, I. Manners, and G. J. Vancso, Chem. Mater. 7, 871 (1995).

39. B. Z. Tang, Y. Geng, J. W. Y. Lam, B. Li, X. Jing, X. Wang, F. Wang, A. B. Pakhomov, and X. X. Zhang, Chem. Mater. 11, 1581 (1999)

40. B. Z. Tang, Y. Geng, Q. Sun, X. Zhang, and X. Jing, Pure Appl. Chem. 72, 157 (2000).

41. R. Petersen, D. A. Foucher, B. Z. Tang, A. Lough, N. P. Raju, J. E. Greedan, and I. Manners, Chem. Mater. 7, 2045 (1995).

42. R. T. Paine and C. K. Narula, Chem. Rev. 90, 73 (1990).

43. D. R. Messier and W. J. Croft, Preparation and Properties of Solid State Materials, W. R. Wilcox, ed. (Dekker, New York, 1982), Vol. 7, Chapt. 2.

44. J. F. Moulder, W. F. Stickle, P. E. Sobol, and K. D. Bomben, in Handbook of X-ray Photoelectron Spectroscopy: a Reference Book of Standard Spectra for Identification and Interpretation 
of XPS Data, J. Chastain, ed. (Physical Electronics Division, Perkin-Elmer Corp., Eden Prairie, MN, 1992).

45. C. S. Fradley, in Electron Spectroscopy, D. A. Shirley, ed. (North-Holland, Amsterdam, 1972).

46. M. Ginzburg, M. J. MacLachlan, S. M. Yang, N. Coombs, T. W. Coyle, N. P. Raju, J. E. Greedan, R. H. Herber, G. A. Ozin, and I. Manners, J. Am. Chem. Soc. 124, 2625 (2002).

47. H. Kim, M. J. Kaufman, and W. M. Sigmund, J. Mater. Res. 19, 1835 (2004).
48. K.-K. Hellwege and A. M. Hellwege, Landolt-Börnstern: Numerical Data and Functional Relationships in Science and Technology (Springer-Verlag, New York, 1970), New Series, Group III, Vol. 4, Part A, Fig. 59.

49. A. Goldman, Handbook of Modern Ferromagnetic Materials (Kluwer, Boston, 1999).

50. D. R. Askeland, The Science and Engineering of Materials, 3rd ed. (PWS, Boston, 1994). 